\title{
Imperfect Reworking Process Consideration in Integrated Inventory Model under Permissible Delay in Payments
}

\author{
Ming-Cheng Lo $^{1}$ and Ming-Feng Yang ${ }^{2}$ \\ ${ }^{1}$ Department of Business Administration, Ching Yun University, Jung 320, Taiwan \\ ${ }^{2}$ Department of Information Management, Yu Da College of Business, Miaoli County 361, Taiwan
}

Correspondence should be addressed to Ming-Cheng Lo, Imc@cyu.edu.tw

Received 20 September 2007; Accepted 24 April 2008

Recommended by Katica Hedrih

This study develops an improved inventory model to help the enterprises to advance their profit increasing and cost reduction in a single vendor single-buyer environment with general demand curve, adjustable production rate, and imperfect reworking process under permissible delay in payments. For advancing practical use in a real world, we are concerned with the following strategy determining, which includes the buyer's optimal selling price, order quantity, and the number of shipments per production run from the vendor to the buyer. An algorithm and numerical analysis are used to illustrate the solution procedure.

Copyright (C) 2008 M.-C. Lo and M.-F. Yang. This is an open access article distributed under the Creative Commons Attribution License, which permits unrestricted use, distribution, and reproduction in any medium, provided the original work is properly cited.

\section{Introduction}

In this highly competitive globalized environment, enterprises are forced to pace their supply according to the requirements of customers. Their initiative to have quick customer response will help them to occupy the market and become the market leaders. Many enterprises attempt to manage their supply chain effectively. One useful technique to achieve this target is to use just-in-time (JIT) and the key to a successful JIT system is to be able to benefit both the vendor and buyer. This is done through the mutual negotiations and agreements on how the savings are divided (Hahn et al. [1]). JIT systems in today's supply chain environment require the creation of a new spirit of cooperation between the buyer and the vendor to gain and maintain a competitive advantage. As Ha and Kim [2] have pointed out, the integrated inventory model can contribute significantly to this vendor-buyer relationship. In Ohta and Furutani's [3] model, a supply chain system, which consists of the supplier, the buyer, and the customer, where the buyer corresponds to a wholesaler, analyzes the effect of customer order cancellations on $(s, S)$ inventory policies for the supplier and the buyer in the supply chain system. 
The spirit of cooperation among enterprises is needed to improve the effectiveness of the supply chain. One of the common strategies in the business cooperation is that the buyers are offered a permissible delay period to pay back for the goods bought without paying any interest. During this period, the buyer does not need to pay interest on goods kept in stock. However, higher interest is charged if the payment for the goods is not paid by the end of this period. For the vendor, he has the benefit of attracting the buyer to purchase his goods in large batches. Therefore, the existence of the permissible delay period will promote a vendor's selling and reduce on-hand stock level. Simultaneously, a buyer can earn the interest of the sales revenue and reduce the holding stock because of the reduced amount of capital invested in stock for the duration of the permissible delay period. Goyal and Cárdenas-Barrón [4] first developed an EOQ model with constant demand rate under conditions of permissible delay in payments. He supposed that no deterioration occurs and the capacity of the warehouse is unlimited. Besides, he also disregarded the difference between the selling price and the purchase cost, and concluded that the economic replenishment time interval and order quantity usually increase marginally under permissible delay in payments. Aggarwal and Jaggi [5] extended the Goyal's model to deteriorating items. Jamal et al. [6] farther extended the model of Goyal [7] to permit shortage and deterioration. Yang and Wee [8] developed a single-vendor, multibuyers inventory policy of a deteriorating item with a constant demand rate. Recently, Teng [9] amended the Goyal's model by considering the difference between the selling price and the purchase cost, and found an alternative conclusion. Abad and Jaggi [10] provided an integrated approach to the vendor for determining his pricing and credit policy when end demand is price sensitive. They considered the vendor-buyer relationship under a noncooperative as well as a cooperative situation and supposed that the vendor follows a lotfor-lot shipment policy. Huang and Yao [11] aimed at optimally coordinating inventory for a deteriorating item among all the partners in a supply chain system with a single vendor and multiple buyers so as to minimize the average total costs. Teng et al. [12] then improved Teng [9] by supposing that demand rate is price sensitive. Ouyang et al. [13] proposed a model with adjustable production rate under the condition of permissible delay in payments. Huang et al. [14] want to extend that fully permissible delay in payments to the supplier would offer the retailer partially permissible delay in payments. The retailer must make a partial payment to the supplier when the order is received. Then the retailer must pay off the remaining balance at the end of the permissible delay period. Their research showed that the trade credit strategy, as permissible delay in payments, could be a win-win strategy. Their analysis also identified that the total channel profit would increase while the vendor and the buyer could cooperate to share necessary business information with each other and balance the rate between production and market demand.

It is impractical that the above integrated vendor-buyer inventory models are assumed that the produced or received products are perfect without any imperfect quality item. In fact, due to the deteriorating production process of the vendor and the damage during the transportation process from the vendor to the buyer, an arrival order batch for the buyer may contain some percentage defectives. Therefore, the conventional integrated inventory model without quality consideration is inappropriate for the situation in which an arrival batch contains some imperfect quality items. Porteus [15] first incorporated the effect of defective items into the classical EOQ model and introduced the alternative of investing in process quality improvement through reducing uncontrollable process quality parameters. Rosenblatt and Lee [16] also considered the effect of an unreliable production process into the EPQ model. 
Their results showed that the average percentage of defective items would be increased by reducing the lot size. Lee and Rosenblatt [17] added process inspection consideration into production runs so that the change, which could move to the process out of control, could be inspected and restored earlier than classical EOQ models. Schwaller [18] extended the EOQ model by joining a known defective rate assumption into the incoming batches and that fixed and variable screening costs are incurred in finding and expelling. Zhang and Gerchak [19] considered a joint lot sizing and inspection policy in an EOQ model where a percentage defective is random. Cheng [20] recommended an EOQ model with demand-dependent unit production cost and imperfect production processes. He formulated the problem as a geometric programing and solved it to get closed-form optimal solutions. Recently, BenDaya and Hariga [21] examined the effect of defective items on production scheduling and established a mathematical model to illustrate the scheduling questions. Salameh and Jaber [22] considered a joint lot sizing and inspection policy under an EOQ model for items with imperfect quality. Their results showed that economic lot size quantity tends to increase as the average percentage of imperfect quality items increase. This contradicts with the finding of Rosenblatt and Lee [16]. They also considered that poor-quality items should be sold as a single batch at a discounted price prior to receiving the next shipment. Hayek and Salameh [23] studied an inventory operating policy under the condition that imperfect quality items would be reworked where shortages are allowed and backordered. Goyal [7] proposed a simple approach to determine the economic production quantity for items with imperfect quality.

From the above-mentioned arguments, for advancing practical use in a real world, this paper develops an integrated inventory model with process unreliability consideration and permissible delay in payments. Imperfect quality items are handled in the same way as proposed in Salameh and Jaber [22]. Yu et al. [24] developed a production-inventory model considering a deteriorating item with imperfect quality and partial backordering. This paper further extends the model of Ouyang et al. [13] to imperfect quality items. The main purpose is to maximize the joint total profit from the perspective of both the vendor and the buyer with the following strategy determining, which includes the buyer's optimal selling price, order quantity, and the number of shipments per production run.

The rest of this paper is organized as follows. The following section describes the notations and assumptions made herein. Section 3 reports on the proposed mathematical model and Section 4 establishes the solution procedure. Section 5 provides numerical examples to illustrate the analysis of Sections 3 and 4 . The final section draws the research conclusions.

\section{Notations and assumptions}

To establish the proposed model, the following notations are used.

\section{Notations}

$D(p)$ : Average demand per year, as a function of the selling price $P$

$A$ : Vendor's production rate, $A>D$

$Q$ : Buyer's order quantity per order

$c_{V}$ : The unit production cost for the vendor

$c_{B}$ : The unit purchasing cost for the buyer

$P$ : The unit selling price for the buyer, a decision variable 
$S_{V}$ : Setup cost per production run for the vendor

$S_{B}$ : Ordering cost per order for the buyer

$h_{V}$ : The unit holding cost rate for the vendor excluding interest charges

$h_{B}$ : The unit holding cost rate for the buyer excluding interest charges

$F$ : Transportation cost per shipment

$n$ : The total number of shipments per production run from the vendor to the buyer,

a positive integer and a decision variable

$L$ : Buyer's replenishment time interval between successive deliveries and a decision variable

$m$ : Buyer's permissible delay period offered by the vendor per order

$I_{V p}$ : Vendor's capital opportunity cost per dollar per year

$I_{B_{P}}$ : Buyer's capital opportunity cost per dollar per year

$I_{B e}$ : Buyer's interest earned per dollar per year

$Z$ : Percentage of defective items in $Q$, a random variable

$f(z)$ : Probability density function of $z$

$\omega$ : The unit inspecting cost

$c_{R}$ : Repair cost per item of imperfect quality for the vendor

$\operatorname{TP}_{V}(n, p, Q)$ : The vendor's total annual profit

$\operatorname{TP}_{B}(p, Q)$ : The buyer's total annual profit

$\operatorname{JTP}(n, p, Q)$ : The joint total annual profit

$\operatorname{ETP}_{V}(n, p, Q)$ : The expected vendor's total annual profit with $Z$

$\operatorname{EJTP}(n, p, Q)$ : The expected joint total annual profit with $Z$.

The assumptions made in the paper are as follows.

Assumptions

(1) There is a single vendor and single buyer for a single product.

(2) The isoelastic curve the most conventionally assumed is selected as a price-demand function form throughout this model and we set $D(p)=\gamma p^{-\beta}$, where $\gamma>0$ is a scaling factor, and $\beta \geq 1$ is an index of price elasticity.

(3) The production rate, $A$, is adjustable. The ratio between the production rate $A$ and the demand rate $D$ was set to be $A / D=\lambda$, where $\lambda>1$ is a constant and $A=\lambda D$.

(4) The buyer orders a quantity of $Q$ for each order with an ordering $\operatorname{cost} S_{B}$; the vendor manufactures at rate $A$, in batches of size $n Q$ with a lot setup cost $S_{V}$; each batch is delivered to the buyer in $n$ equally sized shipments. For each shipment, the buyer brings a transportation cost $F$.

(5) Successive shipments are scheduled so that the next one arrives at the buyer when his stock from previous shipment has just been consumed.

(6) Shortages are not allowed.

(7) The relationship between the buyer's selling price $p$, buyer's purchasing $\operatorname{cost} c_{B}$ and vendor's production cost $c_{V}$ is $p \geq c_{B} \geq c_{V}$.

(8) The vendor offers the buyer a permissible delay period $m$. During this permissible delay period, the buyer sells the items and uses the sales revenue to earn interest at a rate of $I_{B e}$. At the end of this time period, the buyer pays the purchasing cost to the vendor and the items still in stock bring a capital opportunity cost at a rate of $I_{B p}$. 
(9) During the vendor's production process, the produced items are continuously reviewed.

(10) Under JIT manufacturing concept, defective items are not allowed. For maintaining JIT spirit and conforming to the truth, we assume that the reworking of defective items starts instantly they are fund in the same batch cycle and these reworked items are of perfect quality.

(11) In a single batch at the end of the vendor's 100\% inspecting process, if imperfect quality items are found and the repair cost must be paid.

(12) The time horizon is infinite.

\section{Model formulation}

In this section, we formulate the model for the reality assuming that the vendor offers the permissible delay in payments to the buyer and imperfect quality items can be produced during a production run. We make use of the imperfect quality items consideration to extend the integrated inventory model established by Ouyang et al. [13]. Imperfect quality items are occurred in the vendor's production process, and these items can be reworked immediately in the same batch cycle. These imperfect quality items being reworked are of perfect quality. So the vendor delivers an order quantity of $Q$ with perfect quality to the buyer and the buyer accepts it over $n$ times.

Figure 1 depicts the behavior of inventory levels for both the vendor and the buyer, which is along the notations and the assumptions shown above. The joint total annual profit for the vendor and the buyer consists of (3.1) the vendor's total annual profit, and (3.2) the buyer's total annual profit.

\subsection{The vendor's total annual profit}

In each production run, the vendor produces the item in the quantity of $n Q$ with the rate of $A$ and brings a setup cost $S_{V}$ as the buyer places an order of quantity $Q$ over $n$ times. But, the vendor's manufacturing will produce some imperfect quality items. It is assumed that each batch of size $Q$ produced contains percentage defectives $Z Q$. From assumption 10 stated above, the quantity of $Z Q$ with imperfect quality must be reworked instantly when they are fund. These reworked items are excellent in quality. So the vendor's production quantity can be divided into two parts: the quantity of $n(1-Z) Q$ with perfect quality and the reworked quantity of $n Z Q$ with perfect quality. Therefore, the total production quantity for the vendor is still $n Q$ and the buyer would receive it in $n$ batches, which each has a quantity of $Q$ with no defect. Following the above notations and assumptions, the components in the vendor's total annual profit function are

(i) sales revenue per year $=D\left(c_{B}-c_{V}\right)$,

(ii) setup cost per year $=S_{V} / n L=S_{V} D / n Q$,

(iii) inventory holding cost including financing cost per year $=\left(c_{V} h_{V}+c_{V} I_{V p}\right) \times(Q / 2)[n(1-$ $1 / \lambda)-1+2 / \lambda]$

(iv) opportunity cost per year for offering the permissible delay period $m=c_{B} I_{V p} \times D m$,

(v) inspecting cost per year $=c_{R} \times n Z Q / n L=c_{R} Z D$. 


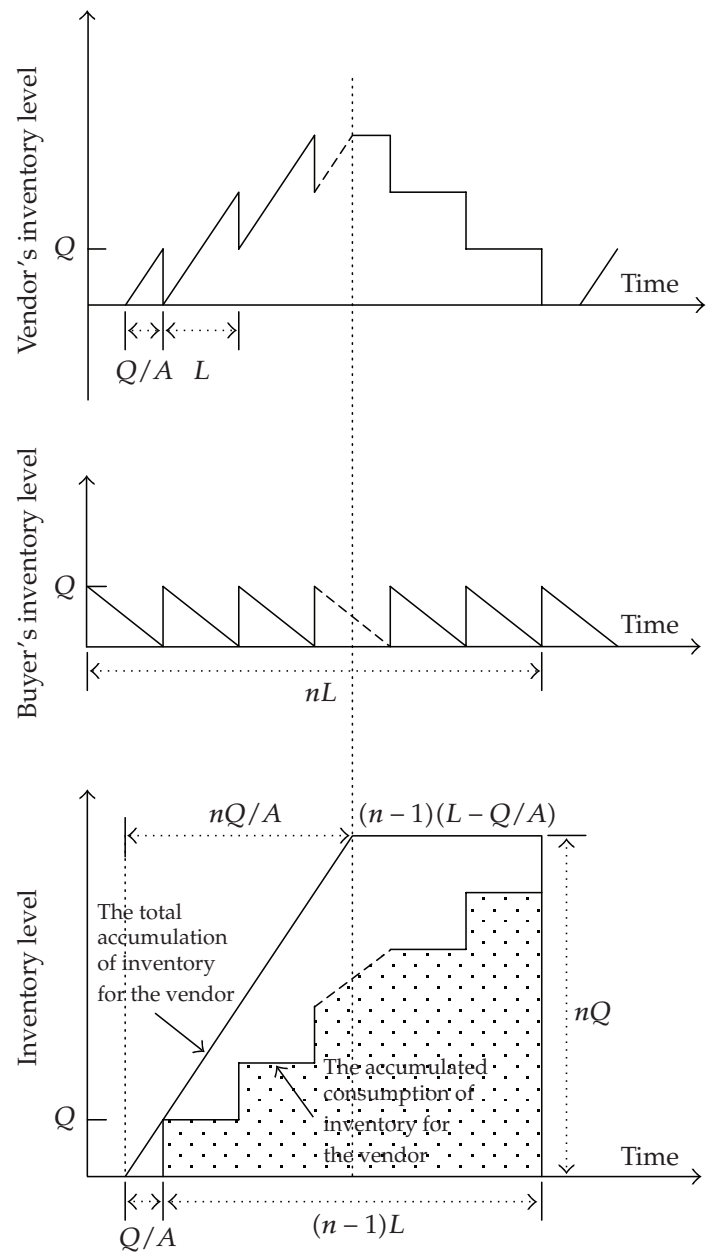

Figure 1: An integrated inventory system for the vendor and the buyer.

Thus, the vendor's total annual profit, $\operatorname{TP}_{V}(n, p, Q)$, can be shown to be

$$
\begin{aligned}
& \mathrm{TP}_{V}(n, p, Q) \\
& \quad=\text { sales revenue }- \text { setup cost }- \text { inspecting cost - holding cost - opportunity cost } \\
& \quad=D\left(c_{B}-c_{V}\right)-\frac{S_{V} D}{n Q}-D \omega-c_{R} Z D-\frac{c_{V} Q\left(h_{V}+I_{V p}\right)}{2}\left[n\left(1-\frac{1}{\lambda}\right)-1+\frac{2}{\lambda}\right]-c_{B} I_{V p} D m .
\end{aligned}
$$

\subsection{The buyer's total annual profit}

In this model, the buyer's replenishment time interval between successive deliveries is $L=$ $Q / D$. The buyer brings an ordering cost $S_{B}$ and a transportation cost $F$ for each order of quantity $Q$. The buyer's total annual profit consists of the following components:

(i) sales revenue per year $=D\left(p-c_{B}\right)$, 


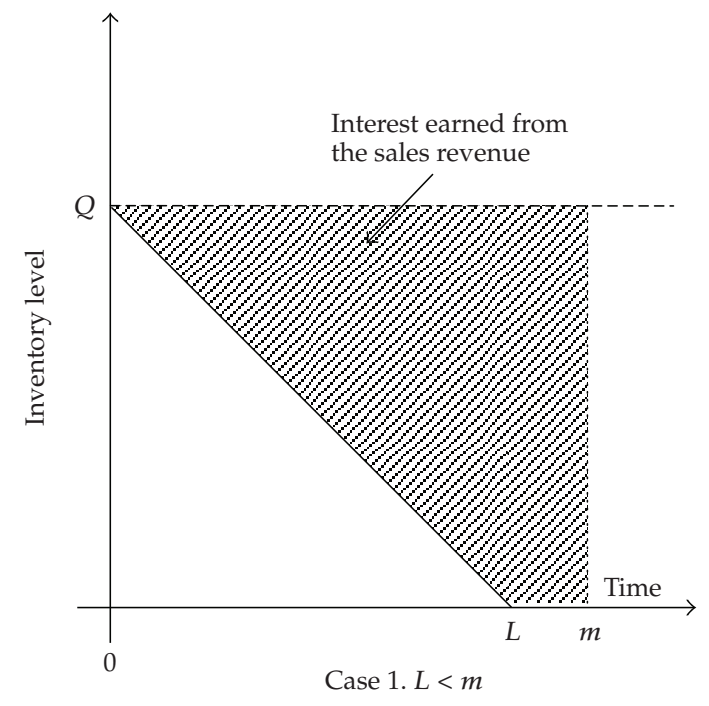

(a)

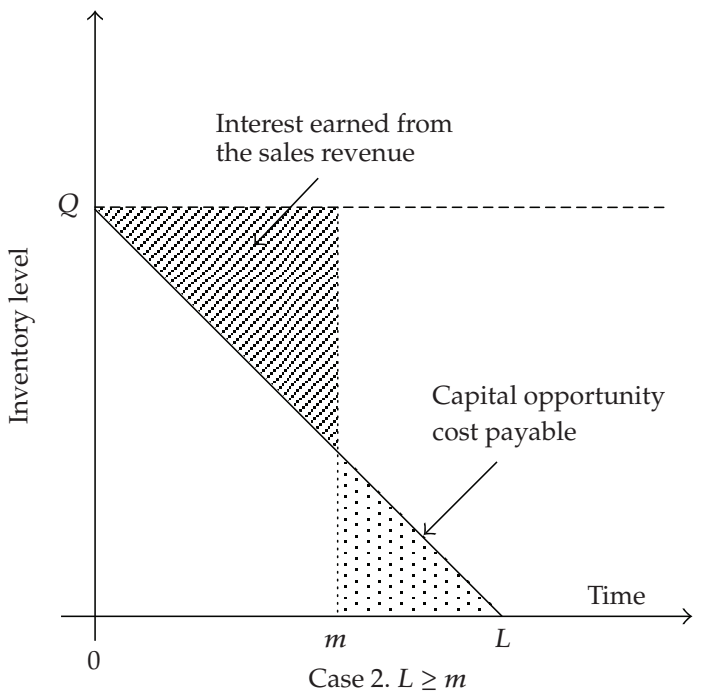

(b)

Figure 2: Inventory systems for the buyer based on the relation between $L$ and $m$.

(ii) cost of placing orders per year $=S_{B} / L=S_{B} D / Q$,

(iii) transportation cost per year $=F / L=F D / Q$,

(iv) inventory holding cost per year $=c_{B} h_{B} \times Q / 2$,

(v) interest earned from the sales revenue received during the permissible delay period $m$,

(vi) capital opportunity cost payable for the items unsold after the permissible delay period $m$ (notice that this cost only exists if $L \geq m$ ).

Considering the components (v) interest earned, and (vi) capital opportunity cost, the model has the following two possible cases based on the values of $L$ and $m$. These two cases are depicted graphically in Figure 2.

Case $1(L<m)$. We first consider Case 1 in Figure 2, where $L<m$, the component (v), the interest earned per year at a rate of $I_{B e}$ in the time span $[0, m]$ is $p I_{B e}(D m-Q / 2)$. In addition, the component (vi), capital opportunity cost payable per year during the time span $[0, m]$ does not exist.

From the above discussions, total profit per year for the buyer, $\operatorname{TP}_{B 1}(p, Q)$, is given by

$$
\begin{aligned}
& \mathrm{TP}_{B 1}(p, Q) \\
& \quad=\text { sales revenue }- \text { ordering cost }- \text { transportation cost }- \text { holding cost }+ \text { interest earned } \\
& \quad=D\left(p-c_{B}\right)-\frac{S_{B} D}{Q}-\frac{F D}{Q}-c_{B} h_{B} \frac{Q}{2}+p I_{B e}\left(D m-\frac{Q}{2}\right) .
\end{aligned}
$$


Case $2(L \geq m)$. For Case 2 in Figure 2, where $L \geq m$, the component (v), the interest earned per year at a rate of $I_{B e}$ during the time span $[0, m]$ is $p I_{B e}(D m)^{2} / 2 Q$. Next, the component (vi), capital opportunity cost payable per year during the time span $[m, L]$ is $c_{B} I_{B p}(Q-D m)^{2} / 2 Q$.

As a result, total profit per year for the buyer, $\operatorname{TP}_{B 2}(p, Q)$, is

$$
\begin{aligned}
\operatorname{TP}_{B 2}(p, Q)= & \text { sales revenue }- \text { ordering cost }- \text { transportation cost }- \text { holding cost } \\
& + \text { interest earned }- \text { opportunity cost } \\
= & D\left(p-c_{B}\right)-\frac{S_{B} D}{Q}-\frac{F D}{Q}-c_{B} h_{B} \frac{Q}{2}+\frac{p I_{B e}(D m)^{2}}{2 Q}-\frac{c_{B} I_{B p}(Q-D m)^{2}}{2 Q} .
\end{aligned}
$$

\subsection{The expected joint total annual profit}

Hence, the joint total annual profit function, $\operatorname{JTP}(n, p, Q)$, can be expressed as

$$
\operatorname{JTP}(n, p, Q)= \begin{cases}\operatorname{JTP}_{1}(n, p, Q)=\operatorname{TP}_{V}(n, p, Q)+\mathrm{TP}_{B 1}(p, Q), & \text { if } L<m \\ \operatorname{JTP}_{2}(n, p, Q)=\operatorname{TP}_{V}(n, p, Q)+\operatorname{TP}_{B 2}(p, Q), & \text { if } L \geq m,\end{cases}
$$

where

$$
\begin{aligned}
\operatorname{JTP}_{1}(n, p, Q)= & D\left(p-c_{V}-\omega-c_{R} Z\right)-\frac{D}{Q}\left(\frac{S_{V}}{n}+S_{B}+F\right)-\frac{c_{V} Q\left(h_{V}+I_{V p}\right)}{2}\left[n\left(1-\frac{1}{\lambda}\right)-1+\frac{2}{\lambda}\right] \\
& -c_{B} I_{V p} D m-c_{B} h_{B} \frac{Q}{2}+p I_{B e}\left(D m-\frac{Q}{2}\right), \\
J_{T P}(n, p, Q)= & D\left(p-c_{V}-\omega-c_{R} Z\right)-\frac{D}{Q}\left(\frac{S_{V}}{n}+S_{B}+F\right)-\frac{c_{V} Q\left(h_{V}+I_{V p}\right)}{2}\left[n\left(1-\frac{1}{\lambda}\right)-1+\frac{2}{\lambda}\right] \\
& -c_{B} I_{V p} D m-c_{B} h_{B} \frac{Q}{2}+\frac{p I_{B e}(D m)^{2}}{2 Q}-\frac{c_{B} I_{B p}(Q-D m)^{2}}{2 Q} .
\end{aligned}
$$

To reduce the notations used by (3.5), we set $Y \equiv c_{V}\left(h_{V}+I_{V p}\right)$. We also replace $Q=D L$ and $D=D(p)=\gamma p^{-\beta}$ into the joint total annual profit function $\operatorname{JTP}(n, p, Q)$. Given that $Z$ is a random variable with a known probability density function $f(z)$. Then we set the expected value of $Z, \mu=E(Z)$ and the expected value of (3.4), $\operatorname{EJTP}(n, p, L)$, is given as

$$
\operatorname{EJTP}(n, p, L)= \begin{cases}\operatorname{EJTP}_{1}(n, p, L)=\operatorname{ETP}_{V}(n, p, L)+\operatorname{TP}_{B 1}(p, L) & \text { if } L<m, \\ \operatorname{EJTP}_{2}(n, p, L)=\operatorname{ETP}_{V}(n, p, L)+\operatorname{TP}_{B 2}(p, L) & \text { if } L \geq m,\end{cases}
$$

where

$\operatorname{EJTP}_{1}(n, p, L)$

$=\gamma p^{-\beta}\left\{p-c_{V}-\omega-c_{R} \mu+\left(p I_{B e}-c_{B} I_{V p}\right) m-\frac{L}{2}\left\{c_{B} h_{B}+p I_{B e}+Y\left[n\left(1-\frac{1}{\lambda}\right)-1+\frac{2}{\lambda}\right]\right\}\right\}-\frac{1}{L}\left(\frac{S_{V}}{n}+S_{B}+F\right)$, 


$$
\begin{aligned}
\operatorname{EJTP}_{2}(n, p, L) \\
=\gamma p^{-\beta}\left\{p-c_{V}-\omega-c_{R} \mu+c_{B}\left(I_{B p}-I_{V p}\right) m-\frac{L}{2}\left\{c_{B}\left(h_{B}+I_{B p}\right)+\gamma\left[n\left(1-\frac{1}{\lambda}\right)-1+\frac{2}{\lambda}\right]\right\}+\frac{\left(p I_{B e}-c_{B} I_{B p}\right) m^{2}}{2 L}\right\} \\
\quad-\frac{1}{L}\left(\frac{S_{V}}{n}+S_{B}+F\right) .
\end{aligned}
$$

\section{Methodology}

The objective of this paper is to find an optimal inventory policy to maximize the joint total annual profit between a vendor and a buyer.

\subsection{Determination of the optimal number of shipments $\boldsymbol{n}$ for any given $\boldsymbol{p}$ and $\mathbf{L}$}

Firstly, taking the first-order and second-order partial derivatives of $\operatorname{EJTP}_{i}(n, p, L)$, for $i=1,2$, with respect to $n$, we obtain

$$
\begin{aligned}
& \frac{\partial \operatorname{EJTP}(n, p, L)}{\partial n}=\left\{\begin{array}{l}
\frac{\partial \operatorname{EJTP}_{1}(n, p, L)}{\partial n} \\
\frac{\partial \operatorname{EJTP}_{2}(n, p, L)}{\partial n}
\end{array}=\frac{-\gamma p^{-\beta} L Y}{2}\left(1-\frac{1}{\lambda}\right)+\frac{S_{V}}{n^{2} L},\right. \\
& \frac{\partial^{2} \operatorname{EJTP}(n, p, L)}{\partial n^{2}}=\left\{\begin{array}{l}
\frac{\partial^{2} \operatorname{EJTP}_{1}(n, p, L)}{\partial n^{2}} \\
\frac{\partial^{2} \operatorname{EJTP}_{2}(n, p, L)}{\partial n^{2}}
\end{array}=-\frac{2 S_{V}}{n^{3} L}<0 .\right.
\end{aligned}
$$

Therefore, for fixed $p$ and $L, \operatorname{EJTP}_{i}(n, p, L)$ is strongly concave on $n>0$ for $i=1,2$. Thus, in each production run, determining the optimal number of shipments $n^{*}$, is simplified to obtain a global optimum.

\subsection{Determination of the optimal replenishment time interval $L$ for any given $n$ and $p$}

By taking the first-order and second-order partial derivatives of $\operatorname{EJTP}_{i}(n, p, L)$, for $i=1,2$, with respect to $L$, we have

$$
\begin{aligned}
& \frac{\partial \operatorname{EJTP}_{1}(n, p, L)}{\partial L}=\frac{-\gamma p^{-\beta}}{2}\left\{c_{B} h_{B}+p I_{B e}+Y\left[n\left(1-\frac{1}{\lambda}\right)-1+\frac{2}{\lambda}\right]\right\}+\frac{1}{L^{2}}\left(\frac{S_{V}}{n}+S_{B}+F\right) \\
& \frac{\partial^{2} \operatorname{EJTP}_{1}(n, p, L)}{\partial L^{2}}=-\frac{2}{L^{3}}\left(\frac{S_{V}}{n}+S_{B}+F\right)<0 \\
& \frac{\partial \operatorname{EJTP}_{2}(n, p, L)}{\partial L} \\
& =\frac{-\gamma p^{-\beta}}{2}\left\{c_{B}\left(h_{B}+I_{B p}\right)+Y\left[n\left(1-\frac{1}{\lambda}\right)-1+\frac{2}{\lambda}\right]+\frac{\left(p I_{B e}-c_{B} I_{B p}\right) m^{2}}{L^{2}}\right\}+\frac{1}{L^{2}}\left(\frac{S_{V}}{n}+S_{B}+F\right) \\
& \frac{\partial^{2} \operatorname{EJTP}_{2}(n, p, L)}{\partial L^{2}}=-\frac{1}{L^{3}}\left[\gamma p^{-\beta} m^{2}\left(c_{B} I_{B p}-p I_{B e}\right)+2\left(\frac{S_{V}}{n}+S_{B}+F\right)\right] .
\end{aligned}
$$


Consequently, $\operatorname{EJTP}_{1}(n, p, L)$ is strongly concave on $L$ for fixed $n$ and $p$. So there exists a unique replenishment time interval value of $L_{1}$, which maximizes $\operatorname{EJTP}_{1}(n, p, L)$. The value of $L_{1}$ can be found by equating (4.2) to be zero, and we obtain

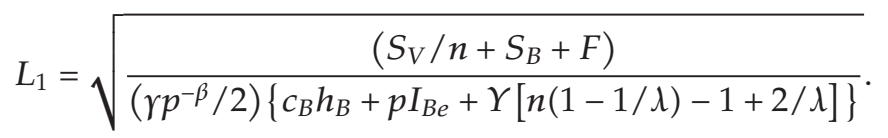

To make certain $L_{1}<m$, we exchange (4.6) into inequality $L_{1}<m$, and get that

$$
\text { iff }\left(\frac{S_{V}}{n}+S_{B}+F\right)<\frac{r p^{-\beta} m^{2}}{2}\left\{c_{B} h_{B}+p I_{B e}+Y\left[n\left(1-\frac{1}{\lambda}\right)-1+\frac{2}{\lambda}\right]\right\}, \quad \text { then } L_{1}<m \text {. }
$$

Then substituting (4.6) into (3.7) and rearranging the result leads to

$\operatorname{EJTP}_{1}(n, p)$

$$
\equiv \operatorname{EJTP}_{1}\left(n, p, L_{1}\right)
$$

$=\gamma p^{-\beta}\left[p-c_{V}-\omega-c_{R} \mu+\left(p I_{B e}-c_{B} I_{V p}\right) m\right]-\sqrt{2 \gamma p^{-\beta}\left(\frac{S_{V}}{n}+S_{B}+F\right)\left\{c_{B} h_{B}+p I_{B e^{+}}+\gamma\left[n\left(1-\frac{1}{\lambda}\right)-1+\frac{2}{\lambda}\right]\right\}}$.

From the inequality (4.7), we know that if $L_{2} \geq m$, it means that

$$
\left(\frac{S_{V}}{n}+S_{B}+F\right) \geq \frac{r p^{-\beta} m^{2}}{2}\left\{c_{B} h_{B}+p I_{B e}+Y\left[n\left(1-\frac{1}{\lambda}\right)-1+\frac{2}{\lambda}\right]\right\} .
$$

Next, we need to check the second-order partial derivative of $\operatorname{EJTP}_{2}(n, p, L)$ for concavity with respect to $L$. The part $Y[n(1-1 / \lambda)-1+2 / \lambda]=Y[((n-1)(\lambda-1)+1) / \lambda]$, where $n \geq 1$ and $\lambda>1$, so it is certainly positive. Accordingly, it follows that

$$
r p^{-\beta} m^{2}\left(c_{B} I_{B p}-p I_{B e}\right)+2\left(\frac{S_{V}}{n}+S_{B}+F\right) \geq r p^{-\beta} m^{2}\left\{c_{B}\left(h_{B}+I_{B p}\right)+Y\left[n\left(1-\frac{1}{\lambda}\right)-1+\frac{2}{\lambda}\right]\right\}>0,
$$

and the polynomial (4.5) is negative. Therefore, $\operatorname{EJTP}_{2}(n, p, L)$ is also strongly concave on $L$ for fixed $n$ and $p$. Similarly, we can obtain an optimum of $L_{2}$ which maximizes $\operatorname{EJTP}_{2}(n, p, L)$. Solving for $L_{2}$ by equating (4.4) to be zero, we have

$$
L_{2}=\sqrt{\frac{\left(S_{V} / n+S_{B}+F\right)+\left(\gamma p^{-\beta} m^{2} / 2\right)\left(c_{B} I_{B p}-p I_{B e}\right)}{\left(\gamma p^{-\beta} / 2\right)\left\{c_{B}\left(h_{B}+I_{B p}\right)+Y[n(1-1 / \lambda)-1+2 / \lambda]\right\}}} .
$$

To make certain $L_{2} \geq m$, we exchange (4.11) into inequality $L_{2} \geq m$, and get that

$$
\text { iff }\left(\frac{S_{V}}{n}+S_{B}+F\right) \geq \frac{r p^{-\beta} m^{2}}{2}\left\{c_{B} h_{B}+p I_{B e}+Y\left[n\left(1-\frac{1}{\lambda}\right)-1+\frac{2}{\lambda}\right]\right\}, \quad \text { then } L_{2} \geq m \text {. }
$$


Substituting (4.11) into (3.8) and rearranging

$$
\begin{aligned}
\operatorname{EJTP}_{2}(n, p) & \\
\equiv & \operatorname{EJTP}_{2}\left(n, p, L_{2}\right) \\
= & \gamma p^{-\beta}\left[p-c_{V}-\omega-c_{R}+c_{B}\left(I_{B p}-I_{V p}\right) m\right] \\
& -\sqrt{2 \gamma p^{-\beta}\left[\left(\frac{S_{V}}{n}+S_{B}+F\right)+\frac{\gamma p^{-\beta} m^{2}}{2}\left(c_{B} I_{B p}-p I_{B e}\right)\right]\left\{c_{B}\left(h_{B}+I_{B p}\right)+\gamma\left[n\left(1-\frac{1}{\lambda}\right)-1+\frac{2}{\lambda}\right]\right\} .}
\end{aligned}
$$

Hence, the above processes on $L$ lead to the following theorem.

Theorem 4.1. For any given $n$ and $p$, we can get the following results.

(i) If $\left(S_{V} / n+S_{B}+F\right)<\left(\gamma p^{-\beta} m^{2} / 2\right)\left\{c_{B} h_{B}+p I_{B e}+Y[n(1-1 / \lambda)-1+2 / \lambda]\right\}$, then $L^{*}=L_{1}$.

(ii) If $\left(S_{V} / n+S_{B}+F\right) \geq\left(\gamma p^{-\beta} m^{2} / 2\right)\left\{c_{B} h_{B}+p I_{B e}+Y[n(1-1 / \lambda)-1+2 / \lambda]\right\}$, then $L^{*}=L_{2}$.

(iii) If $\left(S_{V} / n+S_{B}+F\right)=\left(\gamma p^{-\beta} m^{2} / 2\right)\left\{c_{B} h_{B}+p I_{B e}+Y[n(1-1 / \lambda)-1+2 / \lambda]\right\}$, then $L^{*}=m$.

Proof. The above processes on $L$ imply that Theorem 4.1 holds.

\subsection{Determination of the optimal selling price $p$}

According to Theorem 4.1, we set a function of $p, \psi(p)$, as a distinction function which is given to be

$$
\psi(p)=\frac{\gamma p^{-\beta} m^{2}}{2}\left\{c_{B} h_{B}+p I_{B e}+Y\left[n\left(1-\frac{1}{\lambda}\right)-1+\frac{2}{\lambda}\right]\right\}
$$

$\psi(p)$ is a monotonically decreasing function of $p$, and $p$ is a monotonic variable, where given any $p^{+}>p^{-}$such that $\psi\left(p^{+}\right)<\psi\left(p^{-}\right)$, because

$$
\begin{aligned}
\frac{d \psi(p)}{d p} & =\frac{-\gamma p^{-\beta-1} m^{2}}{2}\left\{\beta\left\{c_{B} h_{B}+Y\left[n\left(1-\frac{1}{\lambda}\right)-1+\frac{2}{\lambda}\right]\right\}+(\beta-1) p I_{B e}\right\} \\
& =\frac{-\gamma p^{-\beta-1} m^{2}}{2}\left\{\beta\left\{c_{B} h_{B}+Y\left[\frac{(n-1)(\lambda-1)+1}{\lambda}\right]\right\}+(\beta-1) p I_{B e}\right\}<0,
\end{aligned}
$$

where $n \geq 1, \lambda>1$ and $\beta>1$.

Utilizing the results in Theorem 4.1, we set $p_{0}$ such that

$$
\left(\frac{S_{V}}{n}+S_{B}+F\right)=\psi\left(p_{0}\right)=\frac{r p_{0}^{-\beta} m^{2}}{2}\left\{c_{B} h_{B}+p_{0} I_{B e}+Y\left[n\left(1-\frac{1}{\lambda}\right)-1+\frac{2}{\lambda}\right]\right\} .
$$

Then for any given $p$ which is substituting into $\psi(p)$, we get

$$
\left(\frac{S_{V}}{n}+S_{B}+F\right) \begin{cases}<\psi(p), & \text { if } p<p_{0} \\ \geq \psi(p), & \text { if } p \geq p_{0} .\end{cases}
$$


By comparing (4.7), (4.12), and (4.17), the following results can be yielded

$$
\begin{aligned}
& \text { iff } p<p_{0}, \quad \text { then } L_{1}<m . \\
& \text { iff } p \geq p_{0}, \quad \text { then } L_{2} \geq m .
\end{aligned}
$$

Consequently, we know from (3.6), (4.8), (4.13), and (4.18) that

$$
\operatorname{EJTP}(n, p)= \begin{cases}\operatorname{EJTP}_{1}(n, p)=\operatorname{EJTP}_{1}\left(n, p, L_{1}\right) & \text { if } p<p_{0} \\ \operatorname{EJTP}_{2}(n, p)=\operatorname{EJTP}_{2}\left(n, p, L_{2}\right) & \text { if } p \geq p_{0}\end{cases}
$$

where $n$ is fixed.

Solving for the optimal selling price $p *$, by taking the first-order partial derivative of (4.8) with respect to $p$ and equating the result to be zero, we obtain

$$
\begin{aligned}
\frac{\partial \operatorname{EJTP}_{1}(n, p)}{\partial p}= & \gamma p^{-\beta}(1-\beta)\left(1+I_{B e} m\right)+\beta \gamma p^{-\beta-1}\left(c_{V}+\omega+c_{R} \mu+c_{B} I_{V p} m\right) \\
& +\sqrt{\frac{r p^{-\beta}\left(S_{V} / n+S_{B}+F\right)}{2}} \times \frac{(\beta / p)\left\{c_{B} h_{B}+p I_{B e}+\gamma[n(1-1 / \lambda)-1+2 / \lambda]\right\}-I_{B e}}{\sqrt{c_{B} h_{B}+p I_{B e}+Y[n(1-1 / \lambda)-1+2 / \lambda]}} \\
= & 0 .
\end{aligned}
$$

Then we need to verify the second-order partial derivative condition for concavity, as

$$
\begin{aligned}
& \frac{\partial^{2} \operatorname{EJTP}_{1}(n, p)}{\partial p^{2}} \\
& =-\beta \gamma p^{-\beta-2}\left[p(1-\text { beta })\left(1+I_{B e} m\right)+(\beta+1)\left(c_{V}+\omega+c_{R} \mu+c_{B} I_{V p} m\right)\right]-\sqrt{\frac{\gamma p^{-\beta-4}\left(S_{V} / n+S_{B}+F\right)}{8}} \\
& \quad \times\left\{(\beta+1) p I_{B e}\left\{2 \beta\left\{c_{B} h_{B}+p I_{B e}+Y\left[n\left(1-\frac{1}{\lambda}\right)-1+\frac{2}{\lambda}\right]\right\}-(\beta+1) p I_{B e}\right\}\right. \\
& \left.\quad+\beta(\beta+2)\left\{c_{B} h_{B}+Y\left[n\left(1-\frac{1}{\lambda}\right)-1+\frac{2}{\lambda}\right]\right\}^{2}\right\}\left\{c_{B} h_{B}+p I_{B e}+Y\left[n\left(1-\frac{1}{\lambda}\right)-1+\frac{2}{\lambda}\right]\right\}^{-3 / 2}<0 .
\end{aligned}
$$

Likewise, taking the first-order partial derivative of (4.13) with respect to $p$ and equating the result to be zero, we get

$$
\begin{aligned}
\frac{\partial \mathrm{EJTP}_{2}(n, p)}{\partial p}= & \beta \gamma p^{-\beta-1}\left[c_{V}+\omega+c_{R} \mu+c_{B}\left(I_{V p}-I_{B p}\right) m\right]+\gamma p^{-\beta}(1-\beta) \\
& +\left\{\frac{\beta}{p}\left(\frac{S_{V}}{n}+S_{B}+F\right)+\gamma p^{-\beta-1} m^{2}\left[\beta c_{B} I_{B p}+\left(\frac{1}{2}-\beta\right) p I_{B e}\right]\right\} \\
& \times \sqrt{\frac{\left(\gamma p^{-\beta} / 2\right)\left\{c_{B}\left(h_{B}+I_{B p}\right)+\gamma[n(1-1 / \lambda)-1+2 / \lambda]\right\}}{\left(S_{V} / n+S_{B}+F\right)+\left(\gamma p^{-\beta} m^{2} / 2\right)\left(c_{B} I_{B p}-p I_{B e}\right)}} \\
= & 0 .
\end{aligned}
$$


Step 1: set $n=1$.

Step 2: determine the $p_{0}$ by solving (4.16).

Step 3: if there exists a $p_{1}$ where $p_{1} \leq p_{0}$, and satisfies both the first-order condition as in (4.20) and the second-order condition as in (4.21), then we compute $L_{1}\left(p_{1}\right)$ by (4.6) and $\operatorname{EJTP}_{1}\left(n, p_{1}\right.$, $\left.L_{1}\left(p_{1}\right)\right)$ by (4.8). If not, we set $\operatorname{EJTP}_{1}\left(n, p_{1}, L_{1}\left(p_{1}\right)\right)=0$.

Step 4: if there exists a $p_{2}$ where $p_{2} \geq p_{0}$, and satisfies both the first-order condition as in (4.22) and the second-order condition as in (4.23), then we compute $L_{2}\left(p_{2}\right)$ by $(4.11)$ and $\operatorname{EJTP}_{2}\left(n, p_{2}\right.$, $\left.L_{2}\left(p_{2}\right)\right)$ by (4.13). If not, we set $\operatorname{EJTP}_{2}\left(n, p_{2}, L_{2}\left(p_{2}\right)\right)=0$.

Step 5: if $\operatorname{EJTP}_{1}\left(n, p_{1}, L_{1}\left(p_{1}\right)\right) \geq \operatorname{EJTP}_{2}\left(n, p_{2}, L_{2}\left(p_{2}\right)\right) . \operatorname{Set} \operatorname{EJTP}(n, p[n], L[n])=\operatorname{EJTP}_{1}\left(n, p_{1}, L_{1}\left(p_{1}\right)\right)$, then $(p[n], L[n])$ is an optimal solution for a given $n$. If not, $\operatorname{EJTP}(n, p[n], L[n])=\operatorname{EJTP}_{2}(n$, $\left.p_{2}, L_{2}\left(p_{2}\right)\right)$.

Step 6: set $n=n+1$, repeat steps $2-5$ to obtain $\operatorname{EJTP}(n, p[n], L[n])$.

Step 7: if $\operatorname{EJTP}(n, p[n], L[n]) \geq \operatorname{EJTP}(n-1, p[n-1], L[n-1])$, go to step 6. If not, go to step 8 and stop.

Step 8: set $\operatorname{EJTP}\left(n^{*}, p^{*}, L^{*}\right)=\operatorname{EJTP}(n-1, p[n-1], L[n-1])$, so $\left(n^{*}, p^{*}, L^{*}\right)$ is an optimal solution. Consequently, the buyer's optimal order quantity per order is $Q^{*}=D\left(p^{*}\right) L^{*}$.

\section{Algorithm 1}

The second-order condition for concavity that we need to verify is

$$
\begin{aligned}
& \frac{\partial^{2} \operatorname{EJTP}_{2}(n, p)}{\partial p^{2}} \\
& =-\gamma p^{-\beta-2}\left\{\beta\left\{(\beta+1)\left[c_{V}+\omega+c_{R} \mu+c_{B}\left(I_{V p}-I_{B p}\right) m\right]+(1-\beta) p\right\}\right. \\
& +\quad \frac{\sqrt{\gamma p^{-\beta}\left\{c_{B}\left(h_{B}+I_{B p}\right)+\gamma[n(1-1 / \lambda)-1+2 / \lambda]\right\}}}{\left[2\left(S_{V} / n+S_{B}+F\right)+m^{2}\left(c_{B} I_{B p}-p I_{B e}\right)\right]^{3 / 2}} \\
& \quad \times\left\{\frac{\beta(\beta+2)}{\gamma p^{-\beta}}\left(\frac{S_{V}}{n}+S_{B}+F\right)^{2}+3 \beta m^{2}\left(\frac{S_{V}}{n}+S_{B}+F\right)\left[c_{B}(\beta+1) I_{B p}-\beta p I_{B e}\right]\right. \\
& \left.\left.\quad+\gamma p^{-\beta} m^{4}\left[\left(\beta^{2}-\frac{1}{4}\right)\left(p I_{B e}\right)^{2}+\beta(2 \beta+1) c_{B} I_{B p} p I_{B e}-\beta(\beta+1)\left(c_{B} I_{B p}\right)^{2}\right]\right\}\right\}
\end{aligned}
$$

$<0$.

\subsection{Optimal solution procedure}

Thus, we can use the following solution procedure to find optimal values $n, p$, and $L$ for this model. The solution procedure is commonly known as dichotomy, as in Algorithm 1. 


\section{Numerical examples}

Example 5.1. Consider an inventory situation with the following parametric values partially adopted in Ouyang et al. [13] and Salameh and Jaber [22]:

(i) scaling factor $\gamma=100000$,

(ii) index of price elasticity $\beta=1.5$,

(iii) ratio between the production rate and the demand rate $\lambda=1.5$,

(iv) purchasing cost for the buyer $c_{B}=\$ 4.5 /$ unit,

(v) ordering cost for the buyer $S_{B}=\$ 10 /$ order,

(vi) buyer's unit holding cost rate $h_{B}=0.111$,

(vii) buyer's capital opportunity cost $I_{B p}=0.08 / \$ / y r$,

(viii) buyer's interest earned rate $I_{B e}=0.06 / \$ / y r$,

(ix) transportation cost $F=\$ 50 /$ shipment,

(x) production cost for the vendor $c_{V}=\$ 2.2 /$ unit,

(xi) setup cost per production run for the vendor $S_{V}=\$ 350 /$ setup,

(xii) vendor's unit holding cost rate $h_{V}=0.046$,

(xiii) vendor's capital opportunity cost $I_{V p}=0.03 / \$ / y r$,

(xiv) inspecting cost $\omega=\$ 0.5 /$ unit,

(xv) repair cost per imperfect quality item $c_{R}=\$ 2 /$ unit.

The percentage defective random variable, $Z$, is uniformly distributed with its probability density function $(P D F)$ as

$$
f(z)= \begin{cases}25, & 0 \leq z \leq 0.04 \\ 0, & \text { otherwise }\end{cases}
$$

Therefore, $\mu=E[Z]=\int_{0}^{0.04} 25 z d z=0.02$.

The above solution algorithm is applied to get the computational results for various values of permissible delay period $m$ as shown in Table 1 .

Table 1 shows that (1) the expected joint total annual profit increases when the permissible delay period $m$ increases, (2) the optimal selling price $p^{*}$ and the optimal replenishment time interval $L^{*}$ are decreasing with the increasing of permissible delay period $m,(3)$ as the annual demand $D\left(p^{*}\right)$ is increasing with the decreasing of $p^{*}$, the buyer's expected total annual profit increases as well as the expected joint total annual profit, and (4) the optimal order quantity $Q^{*}$ decreases with the increasing of permissible delay period within the range of $0<m \leq 70$. Generally speaking, a longer permissible delay period offered may motivate the buyer to carry out frequent shipments in small batches. It also can shorten the replenishment time interval to utilize the credit period in the profit increasing and cost reduction more and more. In addition, it also can be observed from Table 1 that when $m<44$, the vendor's expected total annual profit follows the value of permissible delay period $m$ increasing. But when $m \geq$ 44 , the expected total annual profit of the vendor decreases as the value of permissible delay 
Table 1: Optimal solutions for various values of permissible delay period $m(\lambda=1.50)$.

\begin{tabular}{|c|c|c|c|c|c|c|c|c|c|c|}
\hline \multirow{2}{*}{$\begin{array}{l}m \\
\text { (day) }\end{array}$} & \multirow{2}{*}{$n^{*}$} & \multirow{2}{*}{$p_{0}$} & \multirow{2}{*}{$p^{*}$} & \multirow{2}{*}{$L^{*}$ (day) } & \multirow{2}{*}{$D\left(p^{*}\right)$} & \multirow{2}{*}{$Q^{*}$} & \multirow{2}{*}{$n^{*} Q^{*}$} & \multicolumn{3}{|c|}{ Profit (\$/yr) } \\
\hline & & & & & & & & Vendor & Buyer & Joint \\
\hline 0 & 10 & - & $p_{2}=8.6191$ & $L_{2}=65.9521$ & 3951.9107 & 714.0734 & 7140.7344 & 6542.7743 & 15639.3831 & 22182.1574 \\
\hline 5 & 10 & 0.2313 & $p_{2}=8.6097$ & $L_{2}=65.8780$ & 3958.3844 & 714.4393 & 7144.3930 & 6546.5177 & 15648.1525 & 22194.6702 \\
\hline 10 & 10 & 0.5903 & $p_{2}=8.6007$ & $L_{2}=65.7660$ & 3964.5993 & 714.3443 & 7143.4434 & 6549.8114 & 15658.0354 & 22207.8468 \\
\hline 15 & 10 & 1.0290 & $p_{2}=8.5920$ & $L_{2}=65.6157$ & 3970.6225 & 713.7949 & 7137.9488 & 6552.7706 & 15668.9163 & 22221.6869 \\
\hline 20 & 10 & 1.5361 & $p_{2}=8.5837$ & $L_{2}=65.4278$ & 3976.3830 & 712.7838 & 7127.8381 & 6555.2744 & 15680.9170 & 22236.1914 \\
\hline 25 & 10 & 2.1074 & $p_{2}=8.5758$ & $L_{2}=65.2024$ & 3981.8788 & 711.3094 & 7113.0936 & 6557.3194 & 15694.0429 & 22251.3623 \\
\hline 30 & 10 & 2.7421 & $p_{2}=8.5683$ & $L_{2}=64.9392$ & 3987.1080 & 709.3688 & 7093.6881 & 6558.9020 & 15708.3011 & 22267.2031 \\
\hline 40 & 10 & 4.2066 & $p_{2}=8.5545$ & $L_{2}=64.2988$ & 3996.7599 & 704.0736 & 7040.7364 & 6560.6634 & 15740.2516 & 22300.9150 \\
\hline 41 & 10 & 4.3680 & $p_{2}=8.5532$ & $L_{2}=64.2263$ & 3997.6711 & 703.4398 & 7034.3977 & 6560.7450 & 15743.6916 & 22304.4366 \\
\hline 42 & 10 & 4.5321 & $p_{2}=8.5519$ & $L_{2}=64.1521$ & 3998.5827 & 702.7877 & 7027.8768 & 6560.8266 & 15747.1593 & 22307.9859 \\
\hline 43 & 10 & 4.6991 & $p_{2}=8.5506$ & $L_{2}=64.0763$ & 3999.4946 & 702.1173 & 7021.1732 & 6560.9080 & 15750.6547 & 22311.5627 \\
\hline 44 & 10 & 4.8689 & $p_{2}=8.5494$ & $L_{2}=63.9994$ & 4000.3367 & 701.4221 & 7014.2213 & $6560.8706^{(\mathrm{b})}$ & 15754.2967 & 22315.1673 \\
\hline 45 & 10 & 5.0417 & $p_{2}=8.5482$ & $L_{2}=63.9208$ & 4001.1791 & 700.7085 & 7007.0854 & 6560.8330 & 15757.9668 & 22318.7998 \\
\hline 50 & 10 & 5.9502 & $p_{2}=8.5424$ & $L_{2}=63.5041$ & 4005.2548 & 696.8497 & 6968.4967 & 6560.4028 & 15776.9794 & 22337.3822 \\
\hline 60 & 11 & 8.4755 & $p_{2}=8.5341$ & $L_{2}=60.2724$ & 4011.0993 & 662.3522 & 7285.8737 & 6556.3448 & 15820.4483 & 22376.7931 \\
\hline 70 & 11 & 11.0359 & $p_{1}=8.5309$ & $L_{1}=60.2343$ & 4013.3564 & $662.3060^{(a)}$ & 7285.3655 & 6545.3169 & 15872.9112 & 22418.2281 \\
\hline 80 & 11 & 14.0380 & $p_{1}=8.5280$ & $L_{1}=60.2221$ & 4015.4037 & 662.5092 & 7287.6008 & 6533.9086 & 15925.7575 & 22459.6661 \\
\hline 90 & 11 & 17.5552 & $p_{1}=8.5250$ & $L_{1}=60.2094$ & 4017.5234 & 662.7195 & 7289.9147 & 6522.6064 & 15978.4997 & 22501.1061 \\
\hline
\end{tabular}

period $m$ increases. These results indicate that the buyer can always profit from the permissible delay period. For the vendor, he can also profit from the permissible delay in payments strategy while the credit period of time is not longer than 44 days. But on the contrary, if the permissible delay period $m$ is greater than 44 days, the vendor's expected total annual profit decreases through his sales revenue by permitting the buyer a credit period of time cannot disburse his opportunity cost. Based on the above discussions, it illustrates that applying the permissible delay in payments strategy in an integrated inventory model would advance the profit increasing and cost reduction.

Proceeding to the next, we compare the proposed model herein with the model established by Ouyang et al. [13]. The two models are mainly different from considering imperfect quality items or not. These comparison results are presented in Table 2.

Clearly, it is seen that imperfect quality items cause a significant profit loss. The improvement of the joint profit is greater than $10 \%$. Besides, we also compare the relevant profit of the vendor and the buyer in the proposed model with Ouyang et al. [13] further. The results show that the vendor's profit is downward obviously due to the effect of imperfect quality items. His profit improvement is very big and the improved range is greater than $45 \%$. Table 1 reveals that the optimal selling prices $p^{*}$ s in the situations where the values of permissible delay period $m \in\{0,10,30,60\}$ are all higher than them as in Ouyang et al. [13]. Hence, this causes the annual demand $D\left(p^{*}\right)$ and the optimal order quantity $Q^{*}$ to be smaller than them as in Ouyang et al. [13], this result also induces the damage of the vendor's sales revenue. Furthermore, the process unreliability consideration between the vendor and the buyer will 
Table 2: Comparison results with Ouyang et al. (2005).

\begin{tabular}{|c|c|c|c|c|c|c|c|c|c|}
\hline \multicolumn{10}{|c|}{ Profit $(\$ / y r)$} \\
\hline \multirow[t]{2}{*}{$\stackrel{m}{\text { (day) }}$} & \multicolumn{3}{|c|}{ Joint } & \multicolumn{3}{|c|}{ Vendor } & \multicolumn{3}{|c|}{ Buyer } \\
\hline & This paper & $\begin{array}{l}\text { Ouyang } \\
\text { et al. }\end{array}$ & $\begin{array}{l}\text { Improved } \\
(\%)\end{array}$ & This paper & $\begin{array}{l}\text { Ouyang } \\
\text { et al. }\end{array}$ & $\begin{array}{l}\text { Improved } \\
(\%)\end{array}$ & This paper & $\begin{array}{l}\text { Ouyang } \\
\text { et al. }\end{array}$ & $\begin{array}{l}\text { Improved } \\
(\%)\end{array}$ \\
\hline 0 & 22182.1574 & 24691.0000 & -10.16 & 6542.7743 & 12100.0000 & -45.93 & 15639.3831 & 12591.0000 & 24.21 \\
\hline 10 & 22207.8468 & 24725.0000 & -10.18 & 6549.8114 & 12127.0000 & -45.99 & 15658.0354 & 12598.0000 & 24.29 \\
\hline 30 & 22267.2031 & 24799.0000 & -10.21 & 6558.9020 & 12157.0000 & -46.05 & 15708.3011 & 12642.0000 & 24.25 \\
\hline 60 & 22376.7931 & 24921.0000 & -10.21 & 6556.3448 & 12138.0000 & -45.98 & 15820.4483 & 12783.0000 & 23.76 \\
\hline
\end{tabular}

Table 3: Optimal solutions for various values of $\lambda(m=30)$.

\begin{tabular}{cccccccccccc}
\hline$\lambda$ & $n^{*}$ & $p_{0}$ & $p^{*}$ & $L^{*}$ (day) & $D\left(p^{*}\right)$ & $Q^{*}$ & $n^{*} Q^{*}$ & \multicolumn{3}{c}{ Profit $(\$ /$ yr $)$} \\
& & & & & & & & Vendor & Buyer & Joint \\
\hline 1.01 & 61 & 2.8477 & $p_{2}=8.4577$ & $L_{2}=60.9404$ & 4065.5713 & 678.7876 & 41406.0421 & 6986.0330 & 15571.6602 & 22557.6932 \\
1.10 & 20 & 2.8641 & $p_{2}=8.5068$ & $L_{2}=61.9366$ & 4030.4234 & 683.9196 & 13678.3915 & 6794.9584 & 15632.9216 & 22427.8800 \\
1.50 & 10 & 2.7421 & $p_{2}=8.5683$ & $L_{2}=64.9392$ & 3987.1080 & 709.3688 & 7093.6881 & 6558.9020 & 15708.3011 & 22267.2031 \\
2.00 & 8 & 2.6533 & $p_{2}=8.5947$ & $L_{2}=66.8279$ & 3968.7516 & 726.6397 & 5813.1179 & 6459.0245 & 15739.6967 & 22198.7212 \\
3.00 & 7 & 2.6202 & $p_{2}=8.6158$ & $L_{2}=67.7510$ & 3954.1814 & 733.9719 & 5137.8034 & 6380.2218 & 15764.2464 & 22144.4682 \\
\hline
\end{tabular}

incur the vendor to bear the warranty cost. So the vendor's profit in the proposed model is smaller than it as in Ouyang et al. [13]. But, the buyer's profit is upward, and his profit improvement is greater than $23 \%$. The results reveal that the buyer's profit increment is from his profit raise owing to the higher optimal selling price $p^{*}$ which can pay for the total of his demand decrement owing to the higher optimal selling price $p^{*}$ and the inspecting cost incurred in finding and expelling imperfect quality items. Therefore, the buyer's profit in the proposed model is larger than it as in Ouyang et al. [13]. Then from the above discussions in Table 2, it demonstrates that the proposed model produces a significant profit loss when comparing with the joint total annual profit without considering imperfect quality items. These results have really met the truth.

Example 5.2. We take the same values for the parameters as in Example 5.1. Suppose the value of permissible delay period $m=30$, we investigate the effect of the ratio between the production rate and the demand rate, $\lambda$. Similarly, we also compare the proposed model herein with the model of Ouyang et al. [13]. Following the above solution procedure, the computational results for various values of the ratio $\lambda$ are presented in Table 3.

Table 3 reveals that the expected total annual profit of the vendor and the whole integrated inventory model increase as the value of the ratio $\lambda$ is close to 1 . On the contrary, the buyer's profit decreases. These results are the same as the conclusions in Ouyang et al. [13]. The results imply that if the JIT cooperation between the vendor and the buyer could be implemented successfully, the vendor's profit and the joint profit will increase following that the vendor can get the real time demand rate through the buyer and adjust his production rate to the demand rate. Comparison results between the proposed model and the model of Ouyang et al. [13] are shown in Table 4. The results reveal that the profit improvement of the joint profit is greater than $10 \%$. Obviously, imperfect quality items can lead to a noticeable profit loss. 
Table 4: Comparison results with Ouyang et al. (2005).

\begin{tabular}{|c|c|c|c|c|c|c|c|c|c|}
\hline \multicolumn{10}{|c|}{ Profit (\$/yr) } \\
\hline \multirow[t]{2}{*}{$\lambda$} & \multicolumn{3}{|c|}{ Joint } & \multicolumn{3}{|c|}{ Vendor } & \multicolumn{3}{|c|}{ Buyer } \\
\hline & This paper & $\begin{array}{l}\text { Ouyang } \\
\text { et al. }\end{array}$ & $\begin{array}{l}\text { Improved } \\
(\%)\end{array}$ & This paper & $\begin{array}{l}\text { Ouyang } \\
\text { et al. }\end{array}$ & $\begin{array}{l}\text { Improved } \\
(\%)\end{array}$ & This paper & $\begin{array}{l}\text { Ouyang } \\
\text { et al. }\end{array}$ & $\begin{array}{l}\text { Improved } \\
(\%)\end{array}$ \\
\hline 1.01 & 22557.6932 & 25140.0000 & -10.27 & 6986.0330 & 12758.0000 & -45.24 & 15571.6602 & 12382.0000 & 25.76 \\
\hline 1.10 & 22427.8800 & 24988.0000 & -10.25 & 6794.9584 & 12489.0000 & -45.59 & 15632.9216 & 12499.0000 & 25.07 \\
\hline 1.50 & 22267.2031 & 24799.0000 & -10.21 & 6558.9020 & 12157.0000 & -46.05 & 15708.3011 & 12642.0000 & 24.25 \\
\hline 2.00 & 22198.7212 & 24719.0000 & -10.20 & 6459.0245 & 12017.0000 & -46.25 & 15739.6967 & 12702.0000 & 23.92 \\
\hline 3.00 & 22144.4682 & 24655.0000 & -10.18 & 6380.2218 & 11906.0000 & -46.41 & 15764.2464 & 12749.0000 & 23.65 \\
\hline
\end{tabular}

$m=30$ days.

\section{Conclusions}

This paper investigates a production/inventory situation which producing process would go out of control under permissible delay in payments. In this research, we assume that in the vendor's production process, the imperfect quality items are reworked immediately as they are found and meantime the vendor must bear the repair cost. This new proposed model herein shows a different thought on inventory modeling. The expected joint total annual profit function has been derived. Then by analyzing this derived function, we can obtain the unique closed-form optimal solution for the replenishment time interval and develop a simple solution procedure to determine the buyer's optimal selling price, order quantity, and the number of shipments per production runs from the vendor to the buyer. Finally, the numerical examples adopted in the Ouyang et al. [13] and Salameh and Jaber [22] explain the solution algorithm. These results reveal that applying the permissible delay in payments strategy between the vendor and the buyer can promote the profit increasing and cost reduction. They also indicate that the successful implementation of JIT cooperation in an integrated inventory model leads to the profit rise of the whole inventory model. Besides, the proposed model generates an impressive profit loss when compared with the joint total annual profit without incorporating imperfect quality items into consideration.

\section{References}

[1] C. K. Hahn, P. A. Pinto, and D. J. Bragg, "Just-in-time production and purchasing," Journal of Purchasing and Materials Management, vol. 19, no. 3, pp. 2-10, 1983.

[2] D. Ha and S.-L. Kim, "Implementation of JIT purchasing: an integrated approach," Production Planning E Control, vol. 8, no. 2, pp. 152-156, 1997.

[3] H. Ohta and T. Furutani, "Effect of customer order cancellation on supply chain inventory," Journal of the Chinese Institute of Industrial Engineers, vol. 21, no. 1, pp. 40-45, 2004.

[4] S. K. Goyal and L.E. Cárdenas-Barrón, "Note on: economic production quantity model for items with imperfect quality—a practical approach," International Journal of Production Economics, vol. 77, no. 1, pp. 85-87, 2002.

[5] S. P. Aggarwal and C. K. Jaggi, "Ordering policies of deteriorating items under permissible delay in payments," Journal of the Operational Research Society, vol. 46, no. 5, pp. 658-662, 1995.

[6] A. M. M. Jamal, B. R. Saker, and S. Wang, "An ordering policy for deteriorating items with allowable shortage and permissible delay in payments," Journal of the Operational Research Society, vol. 48, no. 8, pp. 826-833, 1997.

[7] S. K. Goyal, "Economic order quantity under conditions of permissible delay in payments," Journal of the Operational Research Society, vol. 36, no. 4, pp. 335-338, 1985. 
[8] P. C. Yang and H. M. Wee, "A single-vendor multi-buyers integrated inventory policy for a deteriorating item," Journal of the Chinese Institute of Industrial Engineers, vol. 18, no. 5, pp. 23-30, 2001.

[9] J.-T. Teng, "On the economic order quantity under conditions of permissible delay in payments," Journal of the Operational Research Society, vol. 53, no. 8, pp. 915-918, 2002.

[10] P. L. Abad and C. K. Jaggi, "A joint approach for setting unit price and the length of the credit period for a seller when end demand is price sensitive," International Journal of Production Economics, vol. 83, no. 2, pp. 115-122, 2003.

[11] J.-Y. Huang and M.-J. Yao, “On optimally coordinating inventory for a deteriorating item in a supply chain system with a single vendor and multiple buyers," Journal of the Chinese Institute of Industrial Engineers, vol. 22, no. 6, pp. 473-484, 2005.

[12] J.-T. Teng, C.-T. Chang, and S. K. Goyal, “Optimal pricing and ordering policy under permissible delay in payments," International Journal of Production Economics, vol. 97, no. 2, pp. 121-129, 2005.

[13] L.-Y. Ouyang, C.-H. Ho, and C.-H. Su, "Optimal strategy for the integrated vendor-buyer inventory model with adjustable production rate and trade credit," International Journal of Information and Management Sciences, vol. 16, no. 4, pp. 19-37, 2005.

[14] Y.-F. Huang, C.-S. Lai, and M.-L. Shyu, "Retailer's EOQ model with llimited storage space under partially permissible delay in payments," Mathematical Problems in Engineering, vol. 2007, Article ID 90873, 18 pages, 2007.

[15] E. L. Porteus, "Optimal lot sizing, process quality improvement and setup cost reduction," Operations Research, vol. 34, no. 1, pp. 137-144, 1986.

[16] M. J. Rosenblatt and H. L. Lee, "Economic production cycles with imperfect production processes," IIE Transactions, vol. 18, no. 1 , pp. 48-55, 1986.

[17] H. L. Lee and M. J. Rosenblatt, "Simultaneous determination of production cycle and inspection schedules in a production system," Management Science, vol. 33, no. 9, pp. 1125-1136, 1987.

[18] R. L. Schwaller, "EOQ under inspection costs," Production E Inventory Management Journal, vol. 29, no. 3, pp. 22-24, 1988.

[19] X. Zhang and Y. Gerchak, "Joint lot sizing and inspection policy in an EOQ model with random yield," IIE Transactions, vol. 22, no. 1, pp. 41-47, 1990.

[20] T. C. E. Cheng, "An economic order quantity model with demand-dependent unit production cost and imperfect production processes," IIE Transactions, vol. 23, no. 1, pp. 23-28, 1991.

[21] M. Ben-Daya and M. Hariga, "Economic lot scheduling problem with imperfect production processes," Journal of the Operational Research Society, vol. 51, no. 7, pp. 875-881, 2000.

[22] M. K. Salameh and M. Y. Jaber, "Economic production quantity model for items with imperfect quality," International Journal of Production Economics, vol. 64, no. 1-3, pp. 59-64, 2000.

[23] P. A. Hayek and M. K. Salameh, "Production lot sizing with the reworking of imperfect quality items produced," Production Planning E Control, vol. 12, no. 6, pp. 584-590, 2001.

[24] J. C. P. Yu, H.-M. Wee, and J.-M. Chen, “Optimal ordering policy for a deteriorating item with imperfect quality and partial backordering," Journal of the Chinese Institute of Industrial Engineers, vol. 22, no. 6, pp. 509-520, 2005. 


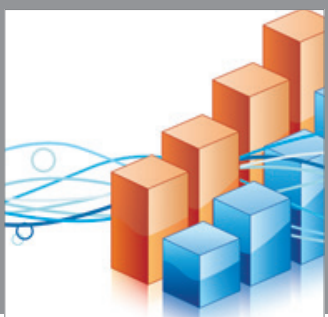

Advances in

Operations Research

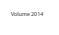

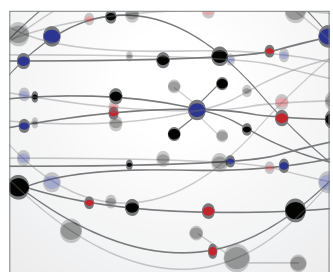

\section{The Scientific} World Journal
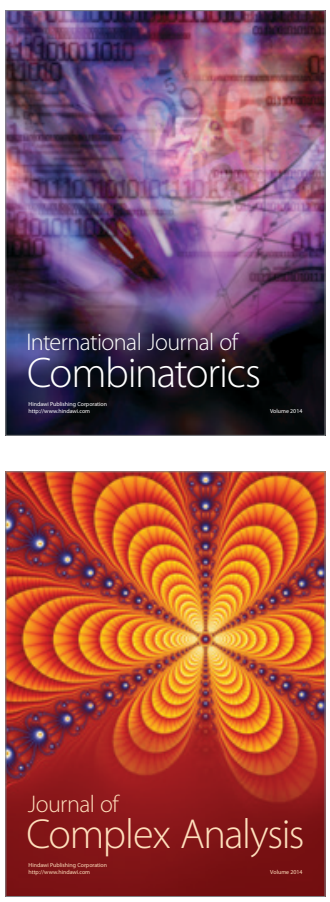

International Journal of

Mathematics and

Mathematical

Sciences
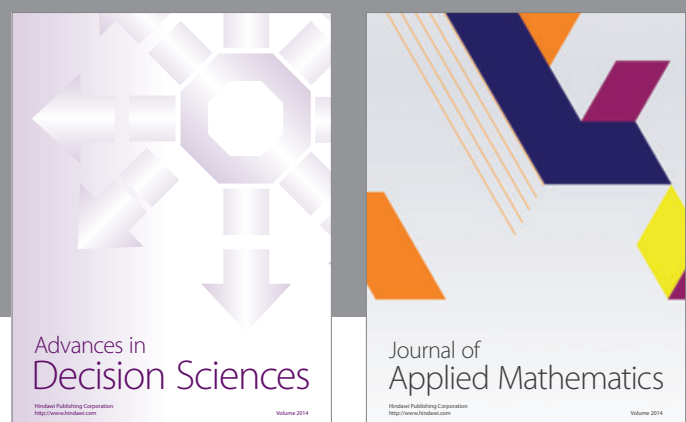

Journal of

Applied Mathematics
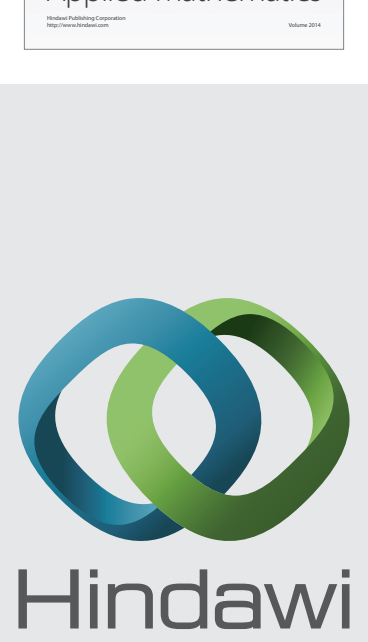

Submit your manuscripts at http://www.hindawi.com
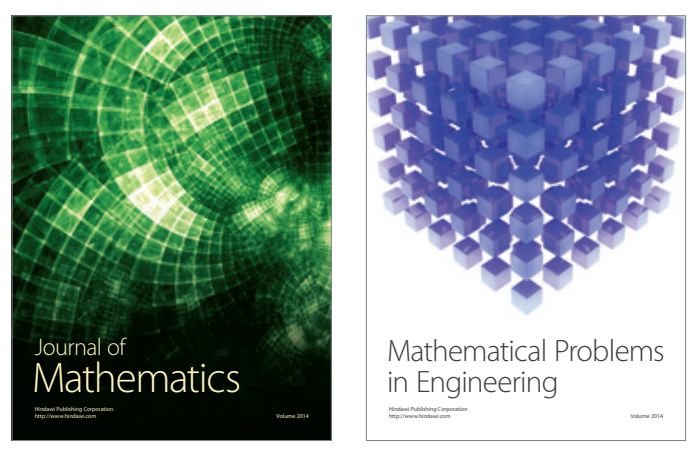

Mathematical Problems in Engineering
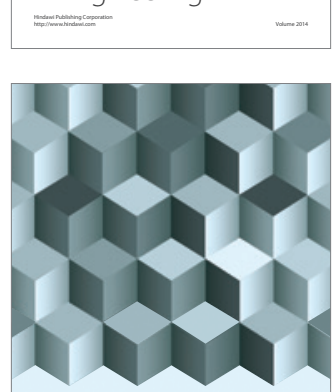

Journal of

Function Spaces
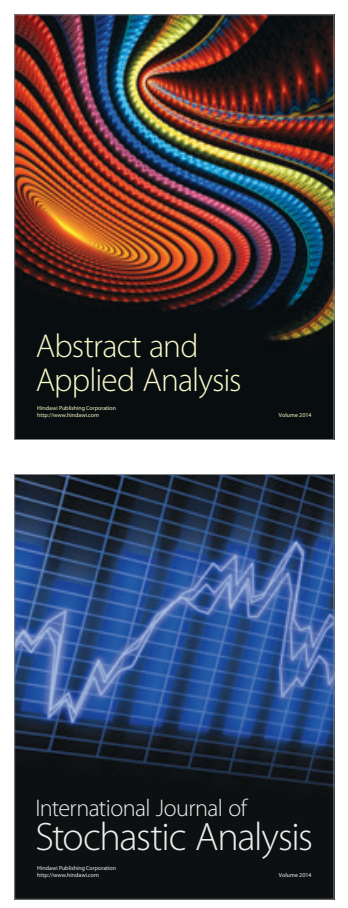

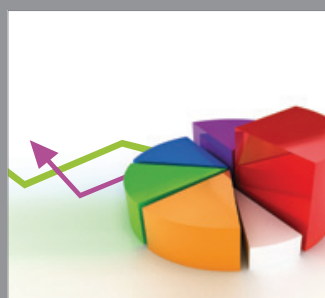

ournal of

Probability and Statistics

Promensencen
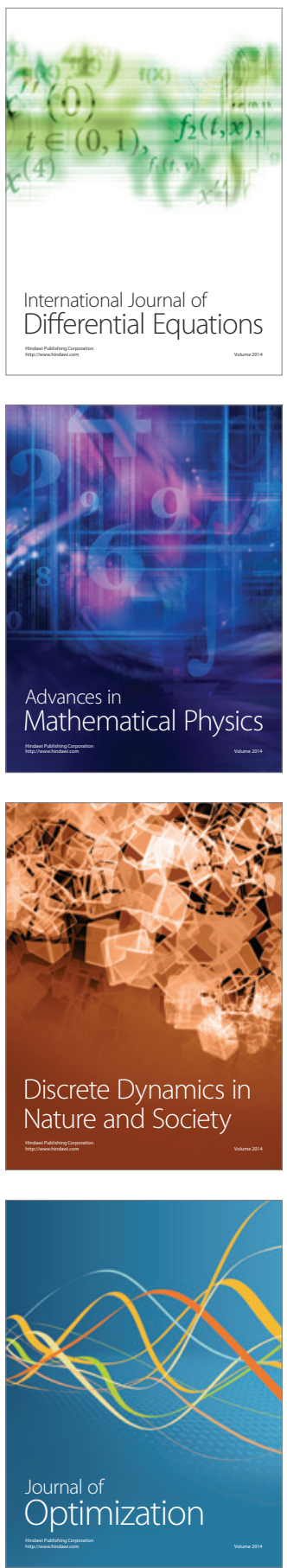